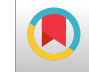

\title{
Association of Urbanization Levels and Colorectal Cancer Incidence in
}

\section{Iran}

\author{
Mostafa Enayatrad ${ }^{1}$, Parvin Yavari ${ }^{2,}{ }^{*}$, Koorosh Etemad ${ }^{3}$, Soheila Khodakarim ${ }^{4}$ and Sepideh Mahdavi ${ }^{5}$ \\ ${ }^{1}$ Department of Epidemiology, Dezful University of Medical Sciences, Dezful, Iran \\ ${ }^{2}$ Department of Community Medicine and Social Determinant of Health Research Center, School of Medicine, Shahid Beheshti University of Medical Sciences, Tehran, Iran \\ ${ }^{3}$ Department of Epidemiology, Environmental and Occupational Hazards Control Research Center, Faculty of Public Health, Shahid Beheshti University of Medical Sciences, \\ Tehran, Iran \\ ${ }^{4}$ Department of Epidemiology, School of Public Health, Shahid Beheshti University of Medical Sciences, Tehran, Iran \\ ${ }^{5}$ Clinical Research Development Unit, Imam Hossein Hospital, Shahroud University of Medical Sciences, Shahroud, Iran \\ "Corresponding author: Parvin Yavari, Department of Community Medicine and Social Determinant of Health Research Center, School of Medicine, Shahid Beheshti University \\ of Medical Sciences, Tehran, Iran. Tel: +98-2122439936, Email: p.yavari-grc@sbmu.ac.ir
}

Received 2018 March 10; Revised 2018 May 16; Accepted 2018 May 21.

\begin{abstract}
Background: Urbanization increases the risk of non-communicable diseases including colorectal cancer by creating changes in lifestyle.

Objectives: We seek, in this study, to create urbanization levels based on various factors affecting urbanization and to investigate its relationship with the colorectal cancer incidence in Iran.

Methods: Using information from census 2011, we collected data on 33 indicators related to urbanization in 31 provinces in Iran. To rank the provinces, we used density-based hierarchical clustering scheme. In order to determine similarities or differences between the provinces, we used the square of the Euclidean distance dissimilarity coefficient; Ward's algorithm was used to merge the provinces to minimize intra-cluster variance. The data obtained from the National Cancer Registry System in 2009 were used to determine the colorectal cancer incidence rate in Iran. One-way ANOVA was used to investigate the association between colorectal cancer incidence and urbanization levels. All statistical analyses were performed, using SPSS (Version 23) software.

Results: Using clustering method, the researchers divided the provinces into 4 different urbanization levels. The results of the ANOVA test indicates a correlation between colorectal cancer incidence and urbanization levels, with a level of significance $(\mathrm{P}=$ $0.001)$ for both genders, $(\mathrm{P}=0.001)$, for men, and $(\mathrm{P}=0.002)$ for women. The findings indicate a difference between the 1 st and 4 th levels as well as between the 2 nd and 4 th levels.

Conclusions: The results of this study showed that considering the lifestyle of people living in higher urban areas, which includes low activity and the use of fast and processed foods, we may claim that residents of these areas are more exposed to the risk factors of this cancer. On the other hand, a higher level of awareness of the residents of these areas and their greater access to health facilities contribute to their further admissions for screening, which can lead to an increase in the number of identified cases of the disease in these areas.
\end{abstract}

Keywords: Colorectal Cancer, Urbanization Levels, Iran, Ecological Study

\section{Background}

Colorectal cancer is the third most common cancer and the 4 th leading cause of cancer- related death worldwide (1). According to the latest figures provided by the International Agency for Research on Cancer in 2012, the incidence of this cancer has been reported to be 20.6 and 14.3 per 100000 people for men and women, respectively $(2,3)$. The highest incidence rate of this cancer is in North America, Western Europe, Australia, and South America, while its lowest incidence rate has been reported in Asia and Africa $(2,4)$. The incidence rate of this disease is decreasing in the United States and Europe (5), but increasing in Asian countries such as China, Japan, South Korea, and Singapore, in which the incidence rate colorectal cancer has increased by 2 to 4 times over the past decades (6).

Colorectal cancer in Iran was reported in 2012 to be the 4th most common cancer with an incidence rate of 11.1 per 100000 people, that is, $6 \%$ to $8 \%$ of all cases of cancer. The incidence rate was reported to be 11.6 and 10.5 per 100000 people for men and women, respectively $(2,7)$. The incidence rate of this cancer in Iran is close to that in other Middle Eastern countries, but much lower than that in the Western countries (8). Colorectal cancer is primarily the disease of developed countries with western culture. In fact, more than $63 \%$ of the cases of this disease occur in developed countries (9). Studies conducted over the past 3 decades have shown that the incidence rate of colorectal 
cancer between 1970 s and 2000 has increased by about $80 \%$ to $100 \%$ in Iran (10-14). A study on populations living in urban areas has shown that factors affecting the urban life affect the etiology of various cancers. Many of these studies have reported higher incidence and mortality rates in urban areas than in rural ones (15).

The proportion of population living in world urban areas has increased from $14 \%$ to over $50 \%$ since the beginning of the 20th century (16), and the number of people living in urban areas was first estimated in 2010 to be more than $50 \%$ of the world's total population (17). It is estimated that more than $70 \%$ of the world's population will be living in urban environments by 2050 (18). These demographic changes are associated with many other changes, including improved public health, improved environmental health, increased access to health care, increased income, changes in the workforce structures, and changes in patterns of food-related and physical activities $(19,20)$. The major drawback of these studies is the lack of a uniform definition of urban and rural areas. Many studies have used population density as an indicator for urban and rural areas $(21,22)$.

One of the major problems in urban studies is the lack of a global standard for the classification of urban environments. In fact, the difference between urban and rural populations among countries is used in the definition, and there are cases of the change of this definition even in one country in the course of time (23).

Urbanization is influenced by many factors and has broad dimensions. Since measuring variables related to different dimensions is not easy or reliable, other factors should be used instead. A measurement based on only one factor can lead to unreliable and instable results. Therefore, the better idea is to combine some of these factors together (23). This is why researchers use several underlying components of urban life, including economic conditions, access to educational and health services, educational levels, employment rates in each economic sector and existing facilities in the urban area, population density and size, access to facilities such as water, electricity, gas, etc., and indices related to communications (telephone, internet, etc.) in order to reduce the problems related to classification between urban and rural areas and the leveling of areas based on urbanization (24-27).

\section{Objectives}

The aim of this study is to create urbanization levels based on various factors affecting urbanization and its association with the colorectal cancer incidence rate in Iran.

\section{Methods}

This is an ecological study conducted to determine the association between urbanization levels and the colorectal cancer incidence rate in Iran. To determine the urbanization levels, the researchers used the statistical yearbook data of Iran's provinces in 2012 as reported in the 7th general consensus. They also used the data available in the National Cancer Registry System extracted from the Ministry of Health and Medical Education, Center for Disease Control and Management, in order to determine the colorectal cancer incidence rate in Iran in 2010. This is an ecological study conducted to assess the correlation between urbanization levels and the colorectal cancer incidence in Iran. In order to determine the levels of urbanization, the statistical data of the provinces of the country, which was reported by the Statistical Center of Iran in 2011 according to the 7th General Census of the country, was used. To obtain the incidence of colorectal cancer, data from the National Cancer Registry System of the Center for Disease Control and Management at the Ministry of Health and Medical Education in 2009 were used.

In order to level the provinces in terms of urbanization, the researchers used a series of variables based on their application in different studies for urbanization levels (25, 28-32), their impact on urbanization, and their availability when the study was being conducted. The variables were classified for the provinces and classified into 7 groups of indices, and totally included 33 variables.

The variables used to determine the urbanization levels include demographic indices (Population size, population relative density, average household size, urbanization factor, and annual growth rate of population), the human resource index (economic participation rate, unemployment rate, share employment in agricultural, industrial, and services sectors), the communication index (Internet penetration rate, penetration rate of mobile and landline phones, and percentage of villages with communications), the energy indices (the rate of electricity use per 1000 population, percentage of rural areas that have electricity, the gas consumption rate per 1000 people, percentage of villages and cities that have gas, and the water consumption rate per 1000 people), the health Indices (ratio of general practitioners per 1000, ratio of nurses per 1000, ratio of specialists per 1000, and ratio of fixed hospital beds per 1000), the human development index (life expectancy at t birth), training index, GDP per capita index, and the urban services and development indices (road density, railroad density, ratio of vehicles per population, ratio of vehicles with identification number per population, per capita green space, and the average area of residential buildings).

The data recorded for colorectal cancer cases in the National Cancer Registry System were extracted from the Min- 
istry of Health and Medical Education, Center for Disease Control and Management (33). Cancer is coded according to the International Classification of Diseases for Oncology (ICD-O) (second edition). The C18-21 code belongs to colorectal cancer. In this study, the incidence rate (age- standardized rate [ASR]) of colorectal cancer for both men and women in all provinces in 2009 was used. To get the standardized incidence of colorectal cancer, the researchers initially separated and classified the new cases by province and gender. Subsequently, after removing duplicates, they prepared the collected data for analysis and calculation of the standardized incidence rate. The standard population of the World Health Organization was considered the standard population and the incidence rate was directly standardized.

The researchers also used hierarchical clustering in order to level the provinces based on the variables. In this method, the number of clusters is not known in advance and the process is either agglomerative or divisive. Indeed, clustering analysis is a method for ranking regions, towns, and villages so that places located on the same level are very similar to each other, but have significant differences with places located at other levels (34). In the agglomerative method, firstly, every observation is placed within a separate cluster and, then, clusters with the highest level of similarity to each other or the least difference are integrated; this process continues and it is repeated until all observations fall into a cluster. In order to perform the agglomerative hierarchical clustering process, we can use different algorithms, which are different from each other in terms of their definitions, gap between two observations, and ways of formation of clusters (35). They used the Euclidean squared distance to determine the similarities or differences between the provinces. After clustering, they used the Ward's minimum variance algorithm so that incluster variance could be minimized. Provinces, whose intrinsic cluster variance was the lowest in terms of scale, were found to be in the lowest cluster and provinces where their intra cluster variance was greater, were found to be in the highest cluster. They also used the analysis of the one-way ANOVA to investigate the relationship between the colorectal cancer incidence rate and urbanization levels. Moreover, they used the Tukey test in case of significance of the results in order to find the differences between the levels. All statistical analyses were done in SPSS version 23. The significance level was considered less than 0.05 .

\section{Results}

The hierarchical clustering results show that 31 provinces of Iran are placed in 4 levels in terms of urbanization (Table 1). Provinces placed at the same level are very similar in terms of the variables used. In this leveling,
Tehran and Alborz provinces are at the highest level of urbanization, whereas Sistan and Baluchestan, Bushehr, Kerman, South Khorasan, North Khorasan, and Hormozgan provinces are at the lowest level of urbanization. Most of the provinces are in the 3rd level (14 provinces), while the fewest of them are in the 1 st level ( 2 provinces).

\begin{tabular}{ll}
\hline Table 1. Leveling the Provinces of the Country Based on Urbanization \\
\hline Urbanization Level & Province \\
\hline Level 1 & Tehran, Alborz \\
Level 2 & $\begin{array}{l}\text { Esfahan, Khorasan Razavi, Khuzestan, Qom, Semnan, } \\
\text { Yazd, Qazvin, Azarbaijan East, Markazi }\end{array}$ \\
Level 3 & $\begin{array}{l}\text { Ardebil, Azarbaijan West, Golestan, Zanjan, } \\
\text { Mazandaran, Gilan, Fars, Lorestan, Ilam, Kohkilouyeh } \\
\text { and Boyerahmad, Chaharmahal and Bakhtiari, } \\
\text { Hamedan, Kermanshah, Kurdistan } \\
\text { Level } 4\end{array}$ \\
& $\begin{array}{l}\text { Bushehr, Hormozgan, Khorasan North, Khorasan } \\
\text { South, Kerman, Sistan and Baluchestan }\end{array}$ \\
\hline
\end{tabular}

According to the latest statistics reported in 2009, the number of cases of colorectal cancer registered in Iran is 5730 cases, of whom the following 5 provinces have the highest number of cases, respectively: Tehran 1836 cases, Khorasan Razavi 438 cases, Isfahan 438 cases, East Azerbaijan 387 cases, and Fars 310 cases, which had $59.49 \%$ of cases of colorectal cancer in Iran altogether with a total number of 3409 cases. The provinces with the highest incidence of colorectal cancer in men are Tehran (16.78), East Azerbaijan (14.41), and Semnan (13.62), and the provinces with the highest incidence rate of colorectal cancer in women are Tehran (17.47), Semnan (14.80), and East Azarbaijan (12.82) per 100000 people (Table 2 ).

According to the results of the ANOVA test (Table 3), on the correlation between the incidence rate of colorectal cancer and urbanization levels, since the level of significance for the incidence rate of both genders $(\mathrm{P}=0.001)$ is $\mathrm{P}=0.001$ for men and $\mathrm{P}=0.002$ for women, which is less than 0.05 , we can thus conclude that there is a significant relationship between urbanization levels and colorectal cancer incidence. The average incidence rate in the 1st level provinces was $12.36 \pm 5.18$ and that in the 4th level provinces was $5.3 \pm 2.3$, which indicates the greater incidence rate of this disease for higher levels than lower ones. The results of the Tukey test in Table 4 indicate a significant difference between the 1st and the 4th levels in both genders $(\mathrm{P}=0.006)$, in men $(\mathrm{P}=0.008)$ and in women $(\mathrm{P}$ $=0.008)$, as well as between the 2nd and the 4 th levels in both genders $(P=0.002)$, in men $(P=0.003)$ and in women $(\mathrm{P}=0.007)$ in terms of the incidence rate of colorectal cancer. 


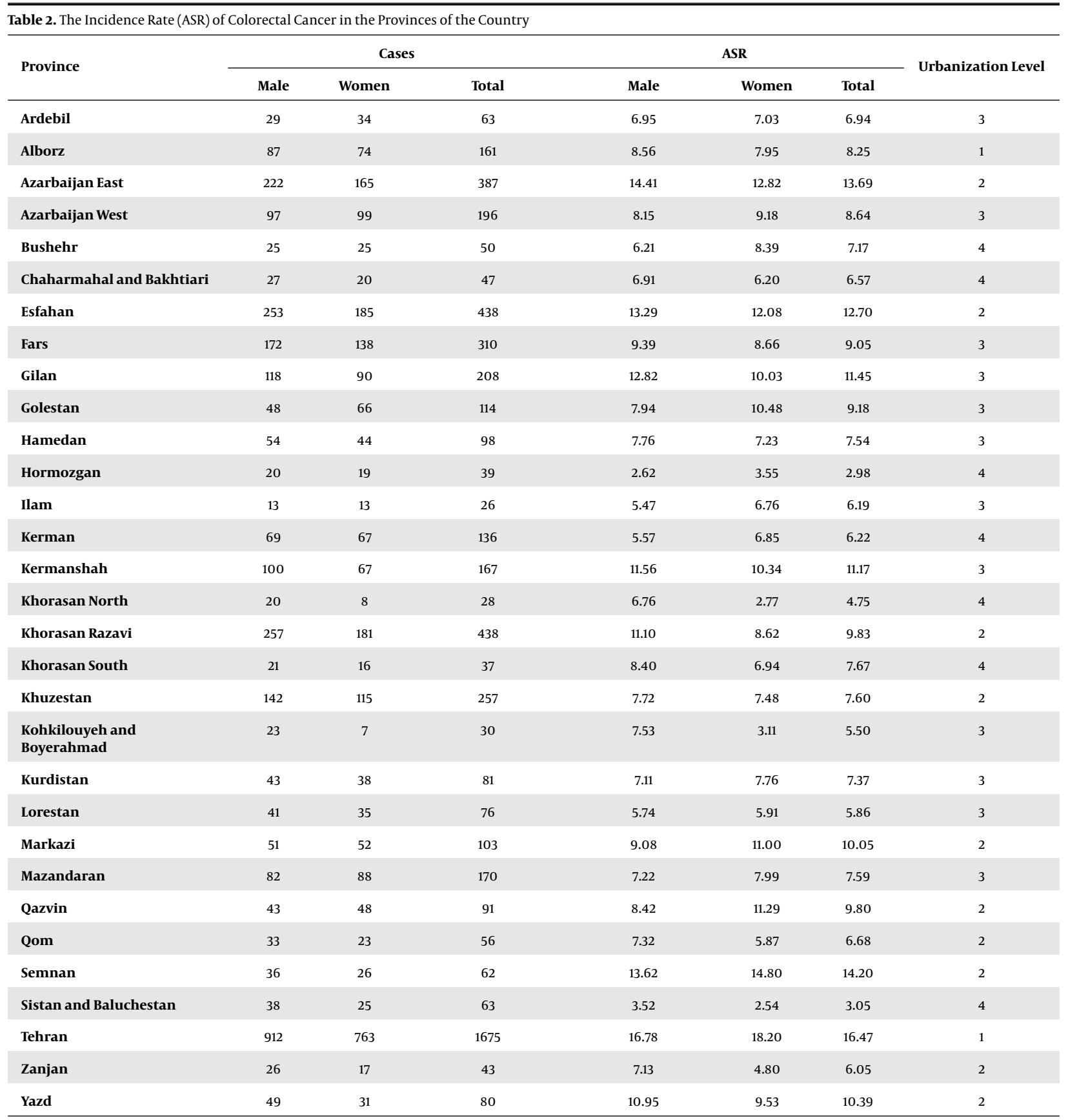

\section{Discussion}

Various components have been used in this study for the leveling of provinces in terms of urbanization. The number of indices used for this purpose includes 7 indices and 33 variables. Attempts have been made in this research to use indices that have a significant impact on the urbanization of Iranian provinces, but it is worth mentioning that these indices only help identify certain angles of urbanization in a region, that is, some of its features are left undiscovered due to limitations for access to statistics and information as well as the weakness of the quantitative methods. Therefore, the new scale explains the problems with the binary rural/urban classification and clarifies the urbanization differences between communities that were not previously evident. Various studies have also calculated the urbanization index in different ways. Darren et al., who used various components for urban- 
Table 3. Relationship Between the Incidence Rate (ASR) of Colorectal Cancer and Urbanization

\begin{tabular}{lccc}
\hline \multirow{2}{*}{ Urbanization Level } & \multicolumn{3}{c}{ Mean CRC in Levels of Urbanization } \\
\cline { 2 - 4 } & \multicolumn{1}{c}{ Total } & Male & Women \\
\hline Level 1 & $12.36 \pm 5.81$ & $12.67 \pm 5.81$ & $13.07 \pm 7.24$ \\
\hline Level 2 & $10.54 \pm 2.57$ & $10.65 \pm 2.67$ & $10.38 \pm 2.78$ \\
\hline Level 3 & $7.79 \pm 1.88$ & $8.02 \pm 2.02$ & $7.51 \pm 2.13$ \\
\hline Level 4 & $5.30 \pm 2.03$ & $5.51 \pm 2.13$ & $5.17 \pm 2.51$ \\
\hline Total & $8.40 \pm 3.10$ & $8.60 \pm 3.16$ & $8.25 \pm 3.45$ \\
\hline P-value & 0.001 & 0.001 & 0.002 \\
\hline
\end{tabular}

Table 4. Determination of the Difference Between Levels in Terms of Incidence Rate (ASR) of Colorectal Cancer

\begin{tabular}{|c|c|c|c|}
\hline \multirow[t]{2}{*}{ Urbanization Level } & \multicolumn{3}{|c|}{ P-Value } \\
\hline & Total & Male & Women \\
\hline \multicolumn{4}{|l|}{ Level 1} \\
\hline Level 2 & 0.766 & 0.731 & 0.604 \\
\hline Level 3 & 0.077 & 0.088 & 0.058 \\
\hline Level 4 & 0.006 & 0.008 & 0.008 \\
\hline \multicolumn{4}{|l|}{ Level 2} \\
\hline Level 3 & 0.053 & 0.086 & 0.094 \\
\hline Level 4 & 0.002 & 0.003 & 0.007 \\
\hline \multicolumn{4}{|l|}{ Level 3} \\
\hline Level 4 & 0.167 & 0.190 & 0.324 \\
\hline
\end{tabular}

ization, showed that a multi-component scale could better show the city/village difference and detect changes between these two environments over time $(24,25)$.

The results of this study indicated a significant difference $(P=0.001)$ between the incidence rate of colorectal cancer and urbanization levels, and a higher incidence rate of colorectal cancer in higher levels of urbanization. Although the lack of a unique definition for urban and rural areas may disrupt the comparison between different studies, most of the previous studies have recorded similar risks in urban areas compared to rural ones. The incidence rate of cancer is higher in urban areas than in rural areas in various countries (36). A study in the United States showed that there is a difference in the incidence and mortality rate of colorectal cancer between the urban and nonurban areas (37). Another study conducted by Coughlin et al. (38) in the United States showed that the incidence rate of colorectal cancer was lower in rural areas than in affluent cities in terms of all subgroups of the study, including age, gender, ethnicity, and race. These differences may be due to exposure to environmental and occupational factors, lifestyle, access to health services, and disease management $(21,39)$.
The previously conducted studies have reported the proportion of urban people with colorectal cancer to be higher than those living in the countryside. Due to the nature of their occupation, the inhabitants of villages have more physical activity, and low level of physical activity is one of the risk factors for cancer. Their special diet, which usually contains vegetables and fresh fruits, also vaccinates them against this disease (40). There is a difference between the characteristics of rural and urban people, which may affect the villagers' response to this disease. The data gathered from several studies have shown that rural people are less concerned about their health problems and that they are less likely to accept the role of a patient in comparison with urban people (41). The villagers' lower income may also limit their access to health care (42). As compared with urban people, villagers are older, poorer, and less educated. They usually have to travel in order to receive health care services and they usually have less access to public transportation (43).

Studies have shown that there is a difference between urban life and rural life in terms of the incidence and mortality rates of colorectal cancer (44). This difference may be due to exposure to environmental and occupational factors, lifestyle, access to health services, and disease management $(39,45,46)$. This inequality in the incidence rate of colorectal cancer can be partly due to the interaction between race and diversity in lifestyle such as physical activity, diet, and colorectal cancer screening. Moreover, there is a lower level of the screening of this cancer among the men and women living in rural areas than that those living in urban areas $(22,47)$. People living in less developed areas or regions with less access to health facilities may have less access to screening for cancer (22). Various studies have shown that living in places of low urbanization levels has an inverse relationship with preventive behaviors (47).

One of the limitations of this study is the lack of access to statistics and data about the incidence rate of colorectal cancer in 2011 due to their lack of dissemination. Therefore, this study used the latest available data disseminated by the Ministry of Health and Medical Education in about the colorectal cancer in 2010. Another limitation in the recorded data is related to different reporting between provinces, which is based in some provinces on population, and in some others on pathology.

\subsection{Conclusions}

In summary, the results of this study indicated a significant difference between the urbanization levels and the incidence rate of colorectal cancer, and a higher incidence rate of this cancer in higher levels of urbanization than in lower ones. Considering the lifestyle of people living in higher urban areas, which includes low activity and the use of fast and processed foods, we may claim that residents of 
these areas are more exposed to the risk factors of this cancer. On the other hand, a higher level of awareness of the residents of these areas and their greater access to health facilities contribute to their further admissions for screening, which can lead to an increase in the number of identified cases of the disease in these areas.

\section{Acknowledgments}

The authors of this article thank the National Iranian Cancer Registry, as well as the Statistical Center of Iran for providing databases. This work was financially supported by the Cancer Research Centre of Shahid Beheshti University of Medical Sciences, Tehran, Iran (IR.SBMU.RETECH.REC.1396.2).

\section{Footnotes}

Authors' Contribution: All authors were responsible for the study conception, design and interpretation of data; and all of them reviewed and approved the final manuscript.

Conflict of Interests: The authors have no conflict of interest in this article.

\section{Financial Disclosure: None declared.}

\section{References}

1. Torre LA, Bray F, Siegel RL, Ferlay J, Lortet-Tieulent J, Jemal A Global cancer statistics, 2012. Cancer J Clin. 2015;65(2):87-108. doi: $10.3322 /$ caac.21262.

2. Ferlay J, Soerjomataram I, Dikshit R, Eser S, Mathers C, Rebelo M, et al. Cancer incidence and mortality worldwide: sources, methods and major patterns in GLOBOCAN 2012. Int J Cancer. 2015;136(5):E359-86. doi: 10.1002/ijc.29210. [PubMed: 25220842].

3. Ghahremani R, Yavari P, Khodakarim S, Etemad K, Khosravi A. [The estimated survival rates for colorectal cancer and related factors in Iran from 1384 to 1388 using the Aalen's additive risk model]. Iran JEpidemiol. 2016;11(4):20-9. Persian.

4. Favoriti P, Carbone G, Greco M, Pirozzi F, Pirozzi RE, Corcione F. Worldwide burden of colorectal cancer: a review. Updates Surg. 2016;68(1):711. doi: 10.1007/s13304-016-0359-y. [PubMed: 27067591].

5. Zheng XE, Li T, Lipka S, Levine E, Vlacancich R, Takeshige U, et al. Location-dependent ethnic differences in the risk of colorectal adenoma: a retrospective multiethnic study. J Clin Gastroenterol. 2014;48(1):e1-7. doi: 10.1097/MCG.0b013e3182834989. [PubMed: 23426462].

6. Sung JJY, Lau JYW, Goh KL, Leung WK. Increasing incidence of colorectal cancer in Asia: implications for screening. Lancet Oncol. 2005;6(11):871-6. doi: 10.1016/s1470-2045(05)70422-8.

7. Enayatrad M, Etemad K, Khodakarim S, Yavari P. The investigate relationship the incidence of colorectal cancer and the human development index in Iran: An ecologic study. Iran J Epidemiol. 2017;13(3):24452.

8. Mirzaei H, Panahi MH, Etemad K, GHanbari-Motlagh A, HolakouieNaini K. Evaluation of pilot colorectal cancer screening programs in Iran. Iran J Epidemiol. 2016;12(3):21-8.

9. Janout V, Kollarova H. Epidemiology of colorectal cancer. Biomedl Papers. 2001;145(1):5-10. doi: 10.5507/bp.2001.001.
10. Malekzadeh R, Bishehsari F, Mahdavinia M, Ansari R. Epidemiology and molecular genetics of colorectal cancer in Iran: a review. Arch Iran Med. 2009;12(2):161-9.

11. Yazdizadeh B, Jarrahi AM, Mortazavi H, Mohagheghi MA, Tahmasebi S, Nahvijo A. Time trends in the occurrence of major GI cancers in Iran Asian Pac J Cancer Prev. 2005;6(2):130-4. [PubMed: 16101320].

12. Rezaianzadeh A, Safarpour AR, Marzban M, Mohaghegh A. A systematic review over the incidence of colorectal cancer in Iran. Ann Colorect Res. 2015;3(1). doi: 10.17795/acr-25724.

13. Almasi SZ, Salehiniya H, Amoori N, Mahdavi S, Enayatrad M. Trends in the incidence of cancer in Iran (2003-2009). Iran J Cancer Prevent. 2017;10(2).

14. Enayatrad M, Mirzaei M, Salehiniya H, Karimirad MR, Vaziri S, Mansouri F, et al. Trends inincidence of common cancers in Iran. Asian Pac J Cancer Prev. 2016;17(S3):39-42. [PubMed: 27165205].

15. Vassallo A, de Stefani E, Ronco A, Barrios E. Urbanization gradients and cancer mortality in Uruguay, 1988-1992. Int J Cancer.1994;59(3):345-50. [PubMed: 7927939].

16. Godfrey R, Julien M. Urbanisation and health. Clin Med (Lond). 2005;5(2):137-41. [PubMed: 15847005].

17. Moore M, Gould P, Keary BS. Global urbanization and impact on health. Int J Hyg Environ Health. 2003;206(4-5):269-78. doi: 10.1078/1438-4639-00223. [PubMed: 12971682].

18. Chen BK, Yang CY. Differences in age-standardized mortality rates for avoidable deaths based on urbanization levels in Taiwan 1971-2008. Int J Environ Res Public Health. 2014;11(2):1776-93. doi: 10.3390/ijerph110201776. [PubMed: 24503974]. [PubMed Central: PMC3945567].

19. Ezzati M, Vander Hoorn S, Lawes CM, Leach R, James WP, Lopez AD et al. Rethinking the "diseases of affluence" paradigm: global patterns of nutritional risks in relation to economic development. PLoS Med. 2005;2(5). e133. doi: 10.1371/journal.pmed.0020133. [PubMed: 15916467]. [PubMed Central: PMC1088287].

20. Popkin BM. The nutrition transition and its health implications in lower-income countries. Public Health Nutr. 1998;1(1):5-21. [PubMed: 10555527].

21. Doll R. Urban and rural factors in the aetiology of cancer. Int J Cancer 1991;47(6):803-10. [PubMed: 2010224].

22. Casey MM, Thiede Call K, Klingner JM. Are rural residents less likely to obtain recommended preventive healthcare services? Am J Prevent Med. 2001;21(3):182-8. doi: 10.1016/s0749-3797(01)00349-x.

23. Cohen B. Urbanization in developing countries: Current trends, future projections, and key challenges for sustainability. Technol Soc. 2006;28(1-2):63-80. doi:10.1016/j.techsoc.2005.10.005.

24. Cohen B, Stren R, Montgomery MR, Reed HE. Cities transformed: Demographic change and its implications in the developing world. Popul Stud. 2005;59(2):259-61.

25. Dahly DL, Adair LS. Quantifying the urban environment: a scale measure of urbanicity outperforms the urban-rural dichotomy Soc Sci Med. 2007;64(7):1407-19. doi: 10.1016/j.socscimed.2006.11.019. [PubMed: 17196724]. [PubMed Central: PMC2001275].

26. Sharma AK. Cities transformed: Demographic change and its implications in the developing world (review). Popul Rev. 2004;43(1). doi 10.1353/prv.2004.0010.

27. Montgomery MR. The urban transformation of the developing world. Sci. 2008;319(5864):761-4. doi: 10.1126/science.1153012. [PubMed: 18258903]

28. McDade TW, Adair LS. Defining the "urban" in urbanization and health: a factor analysis approach. Soc Sci Med. 2001;53(1):55-70. doi: 10.1016/s0277-9536(00)00313-0.

29. Caughy MO, O'Campo PJ, Patterson J. A brief observational measure for urban neighborhoods. Health Place. 2001;7(3):225-36. doi: 10.1016/s1353-8292(01)00012-0.

30. Chen J, Guo F, Wu Y. One decade of urban housing reform in China: Urban housing price dynamics and the role of migration and urbanization, 1995-2005. Habitat Int. 2011;35(1):1-8. doi: 10.1016/j.habitatint.2010.02.003. 
31. Mendez M, Du SF, Popkin B. Urbanization, income and the nutrition transition in China: a case study. FAO. 2004:169-94

32. Gupta A. Measuring urbanization around a regional capital: The case of bhopal district. New Delhi: School of Planning and Architecture; 2013.

33. Goya M. Iranian annual cancer registration report 2003/2008. Ministry of health and medical education, health deputy. Center Dis Control Prevent. 2007;2007.

34. Fanni Z, Razavi M. Level city of Khorasan Razavi province, based on the information society by clustering method. J Humanist Teach. 2013;18(1):53-75.

35. Kaufman AR, Knoll JL, Way BB, Leonard C, Widroff J. Survey of forensic mental health experts on pro se competence after Indiana v. Edwards. J Am Acad Psychiatry Law. 2011;39(4):565-70. [PubMed: 22159986].

36. Crocetti E, Miccinesi G, Paci E, Cislaghi C. What is hidden behind urban and semiurban cancer incidence and mortality differences in central Italy? Tumori. 2002;88(4):257-61. [PubMed: 12400971].

37. Fulton JP, Correa CN, Hirschenberger W. Urbanization and cancer incidence, United States, 1988-1992. In: Howe HL, editor. Cancer incidence in North America, 1989-1993. Sacramento: CA: North American Association of Central Cancer Registries; 1997. p. 1:VI-1-VI-9.

38. Coughlin SS, Richards TB, Thompson T, Miller BA, VanEenwyk J, Goodman MT, et al. Rural/nonrural differences in colorectal cancer incidence in the United States, 1998-2001. Cancer. 2006;107(5 Suppl):11818. doi: 10.1002/cncr.22015. [PubMed: 16802323]

39. Howe HL, Katterhagen JG, Yates J, Lehnherr M. Urban-rural differences in the management of breast cancer. Cancer Causes Control. 1992;3(6):533-9. doi: 10.1007/bfoo052750.
40. Karimi Zarchi AA, Saadat AR, Jalalian HR, Esmaeili M. Kowsar Med J. 2011;15(4):239-43. Persian.

41. Winstead-Fry P, Schultz A. Psychometric analysis of the functional assessment of cancer therapy-general (FACT-G) scale in a rural sample. Cancer. 1997;79(12):2446-52. doi: 10.1002/(sici)10970142(19970615)79:12<2446::aid-cncr23>3.0.co;2-q.

42. Weeks WB, Wallace AE, Wang S, Lee A, Kazis LE. Rural-urban disparities in health-related quality of life within disease categories of veterans. J Rural Health. 2006;22(3):204-11. doi: 10.1111/j.1748-0361.2006.00033.x. [PubMed: 16824163]

43. Miles A, Proescholdbell RJ, Puffer E. Explaining rural/non-rural disparities in physical health-related quality of life: a study of United Methodist clergy in North Carolina. Qual Life Res. 2011;20(6):807-15. doi: 10.1007/s11136-010-9817-z. [PubMed: 21161410].

44. Pickle LW, Feuer EJ, Edwards BK; National Cancer Institute. U.S. predicted cancer incidence, 1999: complete maps by county and state from spatial projection models. Number 5. Bethesda: NIH Publication; 2003.

45. Howe HL, Keller JE, Lehnherr M. Relation between population density and cancer incidence, Illinois, 1986-1990. Am J Epidemiol. 1993;138(1):29-36. [PubMed: 8333424].

46. Singh GK, Miller BA, Hankey BF, Edwards BK. Area socioeconomic variations in US cancer incidence, mortality, stage, treatment, and survival, 1975-1999. cancer surveillance monog s. 2003;4.

47. Coughlin SS, Thompson TD. Colorectal cancer screening practices among men and women in rural and nonrural areas of the United States, 1999. J Rural Health. 2004;20(2):118-24. doi: 10.1111/j.17480361.2004.tb00017.x. 